\title{
Highly-cited estimates of the cumulative incidence and recurrence of vulvovaginal candidiasis are inadequately documented
}

\author{
Sujit D Rathod ${ }^{1,2^{*}+}$ and Patricia A Buffler ${ }^{1+}$
}

\begin{abstract}
Background: Available literature concerning the epidemiologic or clinical features of vulvovaginal candidiasis commonly reports that: $75 \%$ of women will experience an episode of vulvovaginal candidiasis in their lifetimes, 50\% of whom will experience at least a second episode, and 5-10\% of all women will experience recurrent vulvovaginal candidiasis ( $\geq 4$ episodes/1 year). In this debate we traced the three commonly cited statistics to their presumed origins.

Discussion: It is apparent that these figures were inadequately documented and lacked supporting epidemiologic evidence. Population-based studies are needed to make reliable estimates of the lifetime risk of vulvovaginal candidiasis and the proportion of women who experience recurrent candidiasis.
\end{abstract}

Summary: The extent to which vulvovaginal candidiasis is a source of population-level morbidity remains uncertain.

\section{Background}

Vulvovaginal candidiasis is a commonly reported gynecological condition and is diagnosed in a large proportion of women presenting to medical facilities with a complaint of abnormal vaginal discharge [1]. While not a cause of mortality, the morbidity associated with vulvovaginal candidiasis make it a major cause of mental distress [2] and economic costs [3]. Though there are well-recognized limitations of the existing epidemiologic data for vulvovaginal candidiasis [4], frequently-cited incidence and recurrence figures reported in the vulvovaginal candidiasis literature are not, in fact, supported by published epidemiologic studies. Specifically, the literature describing the epidemiologic and clinical features of vulvovaginal candidiasis commonly reports that approximately:

- $75 \%$ of women will experience an episode of vulvovaginal candidiasis in their lifetimes [5-56],

- $50 \%$ of initially infected women will experience at least a second episode $[5,6,8,10,11,13-15,18,20,22-25,27$, $29-33,36-40,44,46,50,51,53]$, and

\footnotetext{
* Correspondence: sujit.rathod@lshtm.ac.uk

${ }^{\dagger}$ Equal contributors

'Division of Epidemiology, University of California, Berkeley, USA

${ }^{2}$ Department of Population Health, London School of Hygiene and Tropical Medicine, London, UK
}

(C) 2014 Rathod and Buffler; licensee BioMed Central Ltd. This is an Open Access article distributed under the terms of the

- $5-10 \%$ of all women experience recurrent vulvovaginal candidiasis (RVVC) ( $\geq 4$ episodes/1 year) $[6,9,11,16$, 18,21,23-26,28,29,31-34,39,43-45,48,51-53,57-62].

An investigation into the sources of these statistics suggests that these commonly reported figures ultimately represent restatements of information derived from unpublished reports and clinical opinion. The regular reference to these undocumented estimates in the literature has developed an "unfounded authority", which masks the need for further study of the epidemiologic features of vulvovaginal candidiasis.

\section{Discussion}

While searching for the primary studies that would provide the epidemiologic support for these statistics, we noted that a number of articles in gynecology journals either directly, or indirectly via intermediary articles, refer to the work of Hurley, with the assertion that, " $75 \%$ of women will experience an episode of vulvovaginal candidiasis in their lifetimes." In 1977, Hurley provided a historical overview of Candida vaginitis at a meeting of experts from the United Kingdom and Belgium [63]. Hurley referred to work by Ajello, stating that "the true incidence and prevalence of mycotic disease remains unknown" [64]. In a later publication, Hurley and de 
Louvois reported that "It is likely that between 1/20 to $1 / 7$ of women of child-bearing years suffer from Candida vaginitis" [65]. It is clear from reading Hurley's cited work that she did not purport to estimate the lifetime incidence of vulvovaginal candidiasis, yet her publications are frequently cited by others to support the $75 \%$ figure.

With regard to the estimate of repeat episodes of vulvovaginal candidiasis experienced by women, Hurley is again directly or indirectly cited by others to support the assertion that: " $50 \%$ of those women will experience at least a second episode [of vulvovaginal candidiasis]." Our search for the source of this estimate indicates that the likely source is a presumably unpublished study Hurley describes in a paper published in 1977: " $A$ retrospective survey of some 500 women treated for pregnancy thrush showed that 45\% had had more than one course of treatment during pregnancy" [63]. Hurley does not provide a reference for this study. Hurley refers to similar results from "unpublished observations" in a paper published in 1975: "A retrospective survey (Hurley and Stanley, 1973) showed that more than half of 300 women treated for pregnancy thrush had had two or more courses of therapy" [2]. The studies to which Hurley refers concern treatment failure - i.e. not of multiple, distinct episodes of vulvovaginal candidiasis - in women during pregnancy, and apparently these estimates were never published in the peer-reviewed literature. Thus, the citations attributed to Hurley do not provide adequate documentation for the $50 \%$ recurrence estimate.

There also does not appear to be adequate support for the statement: "5-10\% of all women experience recurrent vulvovaginal candidiasis." The earliest reference to this estimate was traced to Sobel, who in 1993 stated that: "A small subpopulation of undetermined size, probably less than 5\% of adult women, has recurrent, often intractable, episodes of this disorder" [18]. The previous year Sobel specifically stated "There are no accurate figures describing the magnitude of the group with recurrent infection", which he found was still the case in 2003 "The true incidence of $R V V C$ remains unknown" [66,67]. Though there is ample anecdotal evidence that many women suffer from recurrent vulvovaginal candidiasis, Sobel's publications do not purport to definitively estimate the proportion of the population comprised of these women. Since Sobel's estimate was published there have been two populationbased studies of the prevalence of recurrent vulvovaginal candidiasis, both of which found that approximately $8 \%$ of women are affected by RVVC [3,68]. These studies though the most rigorous available - must be interpreted with caution, as few of the women recruited opted to participate, there was evidence that recall of past diagnoses diminished over time, and the criteria the participants' physicians used to make the diagnoses were unknown.
Though a co-author on these studies, Sobel himself has remarked that the use of self-reported recall of physician diagnoses "multiplies errors", and that other studies are subject to selection bias in the form of women selfselecting to become patients [4].

A limiting characteristic of other studies cited with regard to the cumulative incidence of vulvovaginal candidiasis is the use of self-reported history of vulvovaginal candidiasis [3,13,68-72]. For example, Berg noted that $72 \%$ of 204 adult women visiting a medical center in the United States reported a history of yeast infections [69]. Yet, few authors subsequently citing Berg note the self-reported nature of these data. In their review of genital candidiasis, Achkar and Fries found only two population-based studies of the incidence of vulvovaginal candidiasis, both of which relied on self-reported diagnoses [5]. In the absence of laboratory-confirmation of Candida in women with vulvovaginal candidiasis-associated symptoms, both self-diagnosis and clinical diagnosis are known to be of low accuracy [4,73-76].

Accordingly, diagnostic guidelines from the US Centers of Disease Control recommend use of wet mount, culture or other laboratory tests to confirm the presence of vaginal Candida among women reporting symptoms consistent with vulvovaginal candidiasis [51]. Conversely, population-based studies which only measure vaginal colonization by Candida without clinical examination cannot confirm diagnoses of symptomatic vulvovaginal candidiasis [74]. While it is valuable to understand the incidence of vaginitis, and of vaginal carriage of Candida, neither alone is sufficient to estimate the cumulative incidence or recurrence of vulvovaginal candidiasis.

The peer-reviewed literature on vulvovaginal candidiasis continues to report these unsupported estimates for the incidence and recurrence among all women. One may posit that over time these estimates have fostered an impression among clinicians that women with vaginitis have a high probability of having vulvovaginal candidiasis, so much so that many clinicians dispense with confirmatory tests and rely on syndromic diagnoses. Then, in the words of Sobel: "Misdiagnosis by clinicians inevitably results in incorrect self-diagnosis by patients" [4] - a finding which has been confirmed [77]. These misdiagnoses will continue to manifest themselves in research data which rely on self-reported recall of self- or physician-diagnosed vulvovaginal candidiasis.

Researchers who publish reports concerning vulvovaginal candidiasis continue to cite the publications of Hurley and Sobel. Based on our inquiry into the origins of these estimates in the vulvovaginal candidiasis literature, it appears that these inadequately documented estimates have acquired an "unfounded authority" via repeated citation in the peer-reviewed literature, a phenomena described by Greenberg [78]. 
Population-based cohort studies are essential for providing reasonable estimates of the incidence and recurrence of vulvovaginal candidiasis. A study of this nature requires: 1) a population-based survey of women to identify prevalent infections; 2) prospective follow-up of an initially unaffected cohort for at least one year; 3) laboratory testing for the presence of Candida species upon report of vulvovaginal candidiasis-associated symptoms; and 4) exclusion of Candida as an "innocent bystander" (i.e. when symptoms are a consequence of another condition) [4]. Absent data derived in this manner, it is not possible to make reliable estimates of the incidence and recurrence of vulvovaginal candidiasis in a population.

\section{Summary}

To obtain resources needed for the investigation of a nonlethal health condition, public health researchers must demonstrate that the condition represents a substantial burden on a population level. In the case of vulvovaginal candidiasis, this is contingent on vulvovaginal candidiasis having an unacceptably high incidence and recurrence. As described above, the commonly cited incidence and recurrence figures were not derived from empiric investigation. Thus, the extent to which vulvovaginal candidiasis is a source of population-level morbidity remains uncertain.

\section{Competing interests}

The authors declare that they have no competing interests.

\section{Authors' contributions}

SDR conceived and designed the review of the literature, drafted the manuscript, and revised the manuscript for resubmission. PAB revised the drafts critically for important intellectual content. Both authors analysed and interpreted the results, and have given final approval of the version to be initially submitted.

\section{Acknowledgements}

The authors wish to thank Caitlin E. Gerdts of the University of California, San Francisco, and Benjamin H. Chi and Elizabeth M. Stringer of the Centre for Infectious Disease Research in Zambia at the University of North Carolina, Chapel Hill, for their thoughtful feedback. The statements and opinions expressed here are of the authors alone.

Received: 19 March 2013 Accepted: 5 March 2014

Published: 10 March 2014

\section{References}

1. Anderson MR, Klink K, Cohrssen A: Evaluation of vaginal complaints. JAMA 2004, 291:1368.

2. Hurley R: Inveterate vaginal thrush. Practitioner 1975, 215:753.

3. Foxman B, Barlow R, D'arcy H, Gillespie B, Sobel JD: Candida vaginitis: selfreported incidence and associated costs. Sex Transm Dis 2000, 27:230-235.

4. Sobel JD, Faro S, Force RW, Foxman B, Ledger WJ, Nyirjesy PR, Reed BD, Summers PR: Vulvovaginal candidiasis: Epidemiologic, diagnostic, and therapeutic considerations. Am J Obstet Gynecol 1998, 178:203-211.

5. Achkar JM, Fries BC: Candida infections of the genitourinary tract. Clin Microbiol Rev 2010, 23:253-273.

6. Ahmad A, Khan AU: Prevalence of Candida species and potential risk factors for vulvovaginal candidiasis in Aligarh, India. Eur J Obstet Gynecol Reprod Biol 2009, 144:68-71.

7. Eckert LO, Hawes SE, Stevens CE, Koutsky LA, Eschenbach DA, Holmes KK: Vulvovaginal candidiasis: clinical manifestations, risk factors, management algorithm. Obstet Gynecol 1998, 92:757-765.

8. Eckert LO: Acute vulvovaginitis. NEJM 2006, 355:1244-1252.
9. Marchaim D, Lemanek L, Bheemreddy S, Kaye KS, Sobel JD: Fluconazole-resistant Candida albicans vulvovaginitis. Obstet Gynecol 2012, 120:1407-1414.

10. Ferrer J: Vaginal candidosis: epidemiological and etiological factors. Int J Gynecol Obstet 2000, 71:21-27.

11. Ilkit M, Guzel AB: The epidemiology, pathogenesis, and diagnosis of vulvovaginal candidosis: A mycological perspective. Crit Rev Microbiol 2011, 37:250-261.

12. Nyirjesy P, Seeney SM, Terry Grody MH, Jordan CA, Buckley HR: Chronic fungal vaginitis: the value of cultures. Am J Obstet Gynecol 1995, 173:820-823.

13. Reed BD: Risk factors for Candida vulvovaginitis. Obstet Gynecol 1992, 47:551.

14. Sobel JD: Epidemiology and pathogenesis of recurrent vulvovaginal candidiasis. Am J Obstet Gynecol 1985, 152 (7 Pt 2):924.

15. Xu J, Sobel JD: Antibiotic-associated vulvovaginal candidiasis. Curr Infect Dis Rep 2003, 5:481-487.

16. Mundy RD, Cormack B: Expression of Candida glabrata adhesins after exposure to chemical preservatives. J Infect Dis 2009199 1891-1898.

17. Rodgers C, Beardall A: Recurrent vulvovaginal candidiasis: why does it occur? Int J STD AIDS 1999, 10:435.

18. Sobel JD: Candidal vulvovaginitis. Clin Obstet Gynecol 1993, 36:153.

19. Sobel JD: Vaginitis. NEJM 1997, 337:1896-1903.

20. Sobel JD: Vulvovaginal candidosis. Lancet 2007 369:1961-1971.

21. Spacek J, Buchta V, Jilek P, Forstl M: Clinical aspects and luteal phase assessment in patients with recurrent vulvovaginal candidiasis. Eur J Obstet Gynecol Reprod Biol 2007, 131:198-202.

22. Sobel JD: Pathogenesis and epidemiology of vulvovaginal candidiasis. Ann NY Acad Sci 1988, 544:547-557.

23. Rosa MI, Silva BR, Pires PS, Silva FR, Silva NC, Silva FR, Souza SL, Madeira K, Panatto AP, Medeiros LR: Weekly fluconazole therapy for recurrent vulvovaginal candidiasis: a systematic review and meta-analysis. Eur $J$ Obstet Gynecol Reprod Biol 2013, 167:132-136.

24. Zhou X, Westman R, Hickey R, Hansmann MA, Kennedy C, Osborn TW, Forney $\downarrow$ : Vaginal microbiota of women with frequent vulvovaginal candidiasis. Infect Immun 2009, 77:4130-4135.

25. Abdelmonem AM, Rasheed SM, Mohamed AS: Bee-honey and yogurt: a novel mixture for treating patients with vulvovaginal candidiasis during pregnancy. Arch Gynecol Obstet 2012, 386:109-114

26. Wojitani MDKH, Aguiar LM, Baracat EC, Linhares IM: Association between mannose-binding lectin and interleukin-1 receptor antagonist gene polymorphisms and recurrent vulvovaginal candidiasis. Arch Gynecol Obstet 2011, 285:149-153.

27. Fan S, Liu X: In vitro fluconazole and nystatin susceptibility and clinical outcome in complicated vulvovaginal candidosis. Mycoses 2011, 54:501-505

28. Liu W, Zhang X, Liu Z, Luo X: Impact of $\mathrm{pH}$ on the antifungal susceptibility of vaginal Candida albicans. Int J Gynecol Obstet 2011, 114:278-280.

29. Amouri I, Sellami H, Borji N, Abbes S, Sellami A, Cheikhrouhou F, Maazoun L, Khaled S, Khrouf S, Boujelben Y, Ayada A: Epidemiological survey of vulvovaginal candidosis in Sfax, Tunisia. Mycoses 2011, 54:e499-e505

30. González IDC, González FGB, Cuesta TS, Fernández JM, Rodríguez JMDA, Ferrairo RAE, Alonso MCDH, Arenas LB, Barrientos RR, Wiesmann EC, Romero CD, Diaz YG, Rodriguez-Monino A, Teira BG, del Pozo MS, Horcajuelo JF, Giraldo MJ, Gonzalez PC, Cuadrado RAV, Uriarte BL, Yepes JS, Sanz YH, Pineiro MJI, Hernandez ST, Alonso FG, Gonzalez AIG, Fernandez AS, Carballo C, Lopez AR, Morales F, Lopez DM, GRUPO PRESEVAC: Patient preferences and treatment safety for uncomplicated vulvovaginal candidiasis in primary health care. BMC Public Health 2011, 11:63.

31. Faro S, Faro S: New treatments for vulvovaginal candidiasis. Infect Dis Obstet Gynecol 1996, 4:247-254.

32. Sobel JD: Candida vulvovaginitis. In UpToDate. Edited by Basow DS Waltham, MA: UpToDate; 2011.

33. Sobel JD: Vulvovaginitis. In Female Sexual Pain Disorders: Evaluation and Management. Edited by Goldstein A, Pukall CF, Goldstein I. Hoboken, NJ, USA: Blackwell Publishing; 2009.

34. Ehrström S, Yu A, Rylander E: Glucose in vaginal secretions before and after oral glucose tolerance testing in women with and without recurrent vulvovaginal candidiasis. Obstet Gynecol 2006, 108:1432.

35. Sobel J: Vulvovaginitis in healthy women. Compr Ther 1999, 25:335-346.

36. Rylander E: Vulvovaginal candida in a young sexually active population: prevalence and association with oro-genital sex and frequent pain at intercourse. Sex Transm Infect 2004, 80:54-57. 
37. Walker PP: Vaginal yeasts in the era of "over the counter" antifungals. Sex Transm Infect 2000, 76:437-438.

38. Sobel JD, Brooker D, Stein GE, Thomason JL, Wermeling DP, Bradley B, Weinstein $L$ : Single oral dose fluconazole compared with conventional clotrimazole topical therapy of Candida vaginitis. Am J Obstet Gynecol 1995, 172:1263-1268.

39. Sawyer SM, Bowes G, Phelan PD: Vulvovaginal candidiasis in young women with cystic fibrosis. BMJ 1994, 308:1609.

40. Nelson AL: The impact of contraceptive methods on the onset of symptomatic vulvovaginal candidiasis within the menstrual cycle. Am J Obstet Gynecol 1997, 176:1376-1380.

41. Mathema B, Cross E, Dun E, Park S, Bedell J, Slade B, Williams M, Riley L, Chaturvedi V, Perlin DS: Prevalence of vaginal colonization by drug-resistant Candida species in college-age women with previous exposure to over-the-counter azole antifungals. Clin Infect Dis 2001, 33:e23

42. Beigi RH, Meyn LA, Moore DM, Krohn MA, Hillier SL: Vaginal yeast colonization in nonpregnant women: a longitudinal study. Obstet Gynecol 2004, 104(5, Part 1):926.

43. Fidel PL, Lynch ME, Lopez VR, Sobel JD, Robinson R: Systemic cell-mediated immune reactivity in women with recurrent vulvovaginal candidiasis. J Infect Dis 1993, 168:1458.

44. Patel DA, Gillespie B, Sobel JD, Leaman D, Nyirjesy P, Weitz MV, Foxman B: Risk factors for recurrent vulvovaginal candidiasis in women receiving maintenance antifungal therapy: results of a prospective cohort study. Am J Obstet Gynecol 2004, 190:644-653.

45. Nyirjesy P: Chronic vulvovaginal candidiasis. Am Fam Physician 2001, 63:697.

46. Denning DW: Fortnightly review: Management of genital candidiasis. BMJ 1995, 310:1241-1244.

47. O'Neill S, Howard J: Recurrent vulvovaginal candidiasis. A gynaecological enigma. Aust Fam Physician 1989, 18:99.

48. Osser S, Haglund A, Weström L: Treatment of candidal vaginitis: A prospective randomized investigator-blind multicenter study comparing topically applied econazole with oral fluconazole. Acta Obstet Gynecol Scand 1991, 70:73-78.

49. Corson SL, Kapikian RR, Nehring R: Terconazole and miconazole cream for treating vulvovaginal candidiasis. A comparison. J Reprod Med 1991, 36:561.

50. Sobel JD: Pathophysiology of vulvovaginal candidiasis. J Reprod Med 1989, 34(8 Suppl):572.

51. CDC: Sexually transmitted diseases treatment guidelines, 2010. MMWR 2010, 59(RR12):1-110.

52. Mahmoudi Rad M, Zafarghandi AS, Amel Zabihi M, Tavallaee M, Mirdamadi $Y$ : Identification of Candida species associated with vulvovaginal candidiasis by multiplex PCR. Infect Dis Obstet Gynecol 2012, 2012:1-5.

53. Amouri I, Sellami H, Abbes S, Hadrich I, Mahfoudh N, Makni H, Ayadi A Microsatellite analysis of Candida isolates from recurrent vulvovaginal candidiasis. J Med Microb 2012, 61:1091-1096.

54. Pietrella D, Rachini A, Pines M, Pandey N, Mosci P, Bistoni F, $d^{\prime}$ Enfert C, Vecchiarelli A: Th17 Cells and IL-17 in protective immunity to vaginal candidiasis. PLoS One 2011, 6:e22770.

55. Köhler GA, Assefa S, Reid G: Probiotic interference of Lactobacillus rhamnosus GR-1 and Lactobacillus reuteri RC-14 with the opportunistic fungal pathogen Candida albicans. Infect Dis Obstet Gynecol 2012, 2012:1-14.

56. Yano J, Kolls JK, Happel Kl, Wormley F, Wozniak KL, Fidel PL: The acute neutrophil response mediated by $\mathrm{S} 100$ alarmins during vaginal Candida infections is independent of the Th17-pathway. PLoS One 2012, 7:e46311.

57. Ringdahl EN: Treatment of recurrent vulvovaginal candidiasis. Am Fam Physician 2000, 61:3306.

58. Beikert FC, Le MT, Koeninger A, Technau K, Clad A: Recurrent vulvovaginal candidosis: focus on the vulva. Mycoses 2011, 54:e807-e810.

59. Donders GGG, Mertens I, Bellen G, Pelckmans S: Self-elimination of risk factors for recurrent vaginal candidosis. Mycoses 2011, 54:39-45.

60. Mardh PA, Rodrigues AG, Genc M, Novikova N, Martinez-de-Oliveira J, Guaschino S: Facts and myths on recurrent vulvovaginal candidosis-a review on epidemiology, clinical manifestations, diagnosis, pathogenesis and therapy. Int J STD AIDS 2002, 13:522-539.

61. Watson CJ, Pirotta M, Myers P: Use of complementary and alternative medicine in recurrent vulvovaginal candidiasis-Results of a practitioner survey. Complement Ther Med 2012, 20:218-221.

62. Shokri H, Khosravi AR, Yalfani R: Antifungal efficacy of propolis against fluconazole-resistant Candida glabrata isolates obtained from women with recurrent vulvovaginal candidiasis. Int J Gynecol Obstet 2011, 114:158-159.
63. Hurley R: Candidal vaginitis. Proc R Soc Med 1977, 70(Suppl 4):1

64. Ajello L: The medical mycological iceberg. In The Epidemiology of Human Mycotic Diseases. Edited by Al-Doory Y. Springfield, III: Thomas; 1975:290.

65. Hurley R, de Louvois J: Candida vaginitis. Postgrad Med J 1979, 55:645

66. Sobel JD: Pathogenesis and treatment of recurrent vulvovaginal candidiasis. Clin Infect Dis 1992, 14(Supplement 1):S148.

67. Sobel JD: Management of patients with recurrent vulvovaginal candidiasis. Drugs 2003, 63:1059-1066.

68. Foxman B, Muraglia R, Dietz J-P, Sobel JD, Wagner J: Prevalence of recurrent vulvovaginal candidiasis in 5 European countries and the United States: Results from an internet panel survey. J Lower Genital Tract Dis 2013, 17:340-345.

69. Berg AO, Heidrich FE, Fihn SD, Bergman JJ, Wood RW, Stamm WE, Holmes KK: Establishing the cause of genitourinary symptoms in women in a family practice. JAMA 1984, 251:620.

70. Foxman B: The epidemiology of vulvovaginal candidiasis: risk factors. Am J Pub Health 1990, 80:329.

71. Geiger A, Foxman B, Gillespie B: The epidemiology of vulvovaginal candidiasis among university students. Am J Pub Health 1995, 85(8 Pt 1):1146-1148.

72. Geiger AM, Foxman B: Risk factors for vulvovaginal candidiasis: a casecontrol study among university students. Epidemiology 1996, 7:182-187.

73. Schaaf VM: The limited value of symptoms and signs in the diagnosis of vaginal infections. Arch Internal Med 1929, 1990:150.

74. Odds FC: Candidosis of the genitalia. In Candida and Candidosis. 2nd edition. London, England: Bailliere Tindall; 1988:124-135.

75. Ledger WJ, Monif GRG: A growing concern: Inability to diagnose vulvovaginal infections correctly. Obstet Gynecol 2004, 103:782-784

76. Nyirjesy P, Weitz MV, Grody MH, Lorber B: Over-the-counter and alternative medicines in the treatment of chronic vaginal symptoms. Obstet Gynecol 1997, 90:50-53.

77. Ferris DG, Nyirjesy P, Sobel JD, Soper D, Pavletic A, Litaker MS: Over-the-counter antifungal drug misuse associated with patient-diagnosed vulvovaginal candidiasis. Obstet Gynecol 2002, 99:419-425.

78. Greenberg SA: How citation distortions create unfounded authority: analysis of a citation network. BMJ 2009, 339:b2680.

doi:10.1186/1472-6874-14-43

Cite this article as: Rathod and Buffler: Highly-cited estimates of the cumulative incidence and recurrence of vulvovaginal candidiasis are inadequately documented. BMC Women's Health 2014 14:43.

\section{Submit your next manuscript to BioMed Central and take full advantage of:}

- Convenient online submission

- Thorough peer review

- No space constraints or color figure charges

- Immediate publication on acceptance

- Inclusion in PubMed, CAS, Scopus and Google Scholar

- Research which is freely available for redistribution 